Check for updates

Cite this: Chem. Commun., 2021, 57,8067

Received 19th May 2021,

Accepted 12th July 2021

DOI: $10.1039 / \mathrm{d} 1 \mathrm{cc} 02628 \mathrm{c}$

rsc.li/chemcomm

\section{Ultra-thin films of amphiphilic lanthanide complexes: multi-colour emission from molecular monolayers $\dagger$}

\author{
Alex T. O'Neil, (D) John A. Harrison (D) and Jonathan A. Kitchen (DD*
}

\begin{abstract}
We report the synthesis and Langmuir-Blodgett deposition of 4 brightly emissive lanthanide amphiphiles that can be co-deposited to give multi-emissive ultra-thin films where two, three and four distinct lanthanide emission profiles are observed. To the best of our knowledge, this is the first report of a four-component emissive Langmuir-Blodgett film.
\end{abstract}

The development of advanced multi-functional molecular materials is a highly active research area in modern chemical and materials science. ${ }^{1-3}$ Within this field, luminescent lanthanide-based materials are attractive targets owing to their unique optical properties, e.g. solid-state emission, line-like emission bands, easily tuned quantum yields and long-lived excited states. ${ }^{2-7}$ These characteristics have led to these compounds being used as sensors, ${ }^{7}$ imaging agents, ${ }^{7}$ lasers, ${ }^{8}$ optical displays, ${ }^{8}$ and multi-emissive materials. ${ }^{4,6,9}$ Multi-emissive materials (in this context materials either made up of multiple $\mathrm{Ln}^{3+}$ containing molecular species or molecular species containing two or more $\mathrm{Ln}^{3+}$ ions $)^{10-17}$ in particular are high value targets owing to their propensity towards more advanced and complex applications including molecular barcodes, ${ }^{12}$ ratiometric sensors, ${ }^{13}$ molecular logic gates ${ }^{18}$ and white emissive solids. ${ }^{14,16,19}$ To translate into functional materials, it is desirable to immobilise $\mathrm{Ln}^{3+}$ multiemissive species onto surfaces, however only limited examples exist of surface immobilised multi-emissive species. ${ }^{5,15,16,19-25}$ Langmuir-Blodgett (LB) deposition is promising technique for preparing multi-emissive lanthanide-based thin-films, ${ }^{26,27}$ as it allows for multiple discrete amphiphilic species to be selfassembled into layers - either through sequential building up of layers of different species (multi-layered approach), or through mixing different amphiphiles together prior to deposition (mixed amphiphile approach). ${ }^{22,28}$ Additionally, LB also gives reproducible deposition, and control over film thickness and shape. ${ }^{27,29,30}$

Chemistry, School of Natural and Computational Sciences, Massey University, Auckland, New Zealand. E-mail: J.Kitchen@massey.ac.nz

$\dagger$ Electronic supplementary information (ESI) available: Full synthesis and characterisation details and crystallographic information. CCDC 2046714. For ESI and crystallographic data in CIF or other electronic format see DOI: 10.1039/d1cc02628c
With this in mind we have designed an amphiphilic ligand capable of forming brightly emissive lanthanide complexes for the express purpose of forming multi-emissive films. Utilising our previously developed 1,2,3-triazole "click" synthetic strategy to functionalise 2,6-pyridyldiamides, ${ }^{31}$ we have been able to introduce an alkyl chain for LB deposition into a 2,6-pyridyldicarbonyl core (ligand 1, Fig. 1).

Complexes of $\operatorname{Ln}(\mathbf{1})_{3}$ (where $\operatorname{Ln}=\mathrm{Eu}^{3+}, \mathrm{Tb}^{3+}, \mathrm{Dy}^{3+}, \mathrm{Sm}^{3+}$ and $\mathrm{La}^{3+}$ ) were prepared by refluxing three equivalents of 1 with one equivalent of lanthanide salt [either $\operatorname{Ln}(\mathrm{Cl})_{3} \cdot x_{2} \mathrm{O}$ or $\left.\mathrm{Ln}\left(\mathrm{CF}_{3} \mathrm{SO}_{3}\right) \cdot x \mathrm{H}_{2} \mathrm{O}\right]$ and three equivalents of triethylamine, in DCM:MeOH $(1: 1)$ under microwave irradiation. The resulting clear yellow solutions were subjected to vapour diffusion of diethyl ether which resulted in off-white precipitates. Decanting off the solvent and air drying the precipitates yielded off-white solids in good yields (51-77\%). Complex formation was confirmed by elemental analysis, IR and HRMS (see ESI $\dagger$ for details). Lanthanide coordination within the $\mathrm{NO}_{2}$ pocket is suggested by the notable shift to lower energy for both the $\mathrm{C}=\mathrm{O}$ stretches from $1745 \mathrm{~cm}^{-1}$ (carboxyl) and $1669 \mathrm{~cm}^{-1}$ (amide) to a merged peak at $1636-3 \mathrm{~cm}^{-1}$, a shift commonly associated with coordination to $\mathrm{Ln}^{3+}$ ions. ${ }^{32}$

Photophysical properties of 1 and the $\operatorname{Ln}(\mathbf{1})_{3}$ complexes were measured using $0.01 \mathrm{mM}$ solutions in either $\mathrm{MeOH}$ or $\mathrm{MeCN}$. The absorption spectra of 1 showed an intense peak at $222 \mathrm{~nm}$ and a broad three peak signal $(265,271$ and $280 \mathrm{~nm})$, with the latter assigned to the $\mathrm{n} \rightarrow \pi^{*}$ and $\pi \rightarrow \pi^{*}$ transitions from the central pyridyl unit as seen in previous studies. ${ }^{33,34}$ Similar UV-absorption spectra are observed for $\operatorname{Ln}(\mathbf{1})_{3}$ however, they show a slight red shift in the broad peak at $\sim 270 \mathrm{~nm}$ and a significant increase in the absorbance.

The solid lanthanide complexes (excluding non-emissive $\mathrm{La}^{3+}$ ) showed classical lanthanide emission under short-wave UV irradiation (Fig. 1b). Solution based photoluminescence studies were carried out on all emissive complexes with an excitation wavelength of $275 \mathrm{~nm}$. $\operatorname{Eu}(\mathbf{1})_{3}$ showed the expected red emission from the $\mathrm{Eu}^{3+}$ with ${ }^{5} \mathrm{D}_{0} \rightarrow{ }^{7} \mathrm{~F}_{\mathrm{J}}(J=0-4)$ transitions. $\operatorname{Tb}(\mathbf{1})_{3}, \operatorname{Sm}(\mathbf{1})_{3}$ and $\operatorname{Dy}(\mathbf{1})_{3}$ also exhibited the typical emissive 

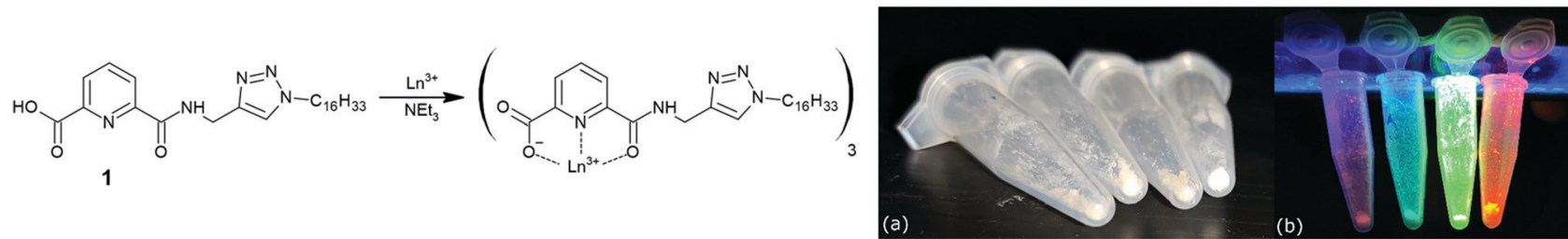

Fig. 1 - (Left) Reaction scheme for generating $\operatorname{Ln}(\mathbf{1})_{3}$ complexes from 1. (Right) (a) Lanthanide complexes $\operatorname{Ln}(\mathbf{1})_{3}$ without excitation source and (b) under shortwave UV irradiation: left to right $-\mathrm{Sm}(\mathbf{1})_{3}, \mathrm{Dy}(\mathbf{1})_{3}, \mathrm{~Tb}(\mathbf{1})_{3}$ and $\mathrm{Eu}(\mathbf{1})_{3}$.

transitions from ${ }^{5} \mathrm{D}_{4}$ depopulation to corresponding ${ }^{7} \mathrm{~F}_{\mathrm{J}}$ $(J=6-3),{ }^{4} \mathrm{G}_{5 / 2}$ depopulation to ${ }^{6} \mathrm{H}_{\mathrm{J}}(J=5 / 2-11 / 2)$ and ${ }^{4} \mathrm{~F}_{9 / 2}$ depopulation to ${ }^{6} \mathrm{H}_{\mathrm{J}}(J=15 / 2-9 / 2)$ respectively. Notably for $\operatorname{Dy}(\mathbf{1})_{3}$, the overall emission appears close to white with CIE coordinates of $x=0.3346$ and $y=0.3829$ (pure white emission being $x, y=0.33),{ }^{14}$ owing to the combination of its emissive blue $\left({ }^{4} \mathrm{~F}_{9 / 2} \rightarrow{ }^{6} \mathrm{H}_{15 / 2}\right)$, yellow $\left({ }^{4} \mathrm{~F}_{9 / 2} \rightarrow{ }^{6} \mathrm{H}_{15 / 2}\right)$ and weaker red $\left({ }^{4} \mathrm{~F}_{9 / 2} \rightarrow{ }^{6} \mathrm{H}_{11 / 2}\right.$ and $\left.9 / 2\right)$ transitions (Figs. S65, S81 ESI $\left.\dagger\right) .{ }^{35}$ Lifetime measurements for $\operatorname{Eu}(\mathbf{1})_{3}$ and $\mathrm{Tb}(\mathbf{1})_{3}$, gave values of 1.960 and $0.984 \mathrm{~ms}$ respectively which fit to single exponential decay functions indicative of single species emission. Excitation plots of the major emitting peaks $\mathrm{Eu}^{3+}(616 \mathrm{~nm}), \mathrm{Tb}^{3+}(545 \mathrm{~nm}), \mathrm{Dy}^{3+}$ $(480$ and $573 \mathrm{~nm})$ and $\mathrm{Sm}^{3+}(600 \mathrm{~nm})$, showed similar spectral features $(200 \mathrm{~nm}$ to $300 \mathrm{~nm})$ to their electronic absorption spectra with two major excitation points around $230 \mathrm{~nm}$ and $275 \mathrm{~nm}$, indicating the population of lanthanide excited states through indirect excitation. Overall quantum yields of the emissive lanthanide complexes were calculated by the relative method $^{36}$ in $\mathrm{MeOH}$ by comparing to $\mathrm{Cs}_{3}\left[\mathrm{Eu}(\mathrm{dpa})_{3}\right] \cdot 8 \mathrm{H}_{2} \mathrm{O}$ and $\mathrm{Cs}_{3}\left[\mathrm{~Tb}(\mathrm{dpa})_{3}\right] \cdot 8 \mathrm{H}_{2} \mathrm{O}$ standards. ${ }^{37} \mathrm{Eu}(\mathbf{1})_{3}, \mathrm{~Tb}(\mathbf{1})_{3}$ and $\mathrm{Dy}(\mathbf{1})_{3}$ gave quantum yields of $22.4 \%, 11.9 \%$ and $2.9 \%$, whilst $\operatorname{Sm}(\mathbf{1})_{3}$ gave a lower yield of $0.32 \%$.

We next investigated the ability of the $\operatorname{Ln}(\mathbf{1})_{3}$ complexes to self-assemble at an air-water interface and form Langmuir films. $20 \mu \mathrm{L}$ aliquots of complex (using $\mathrm{CHCl}_{3}: \mathrm{MeOH}(20: 1)$ as the spreading solvent) were applied onto the surface of a pure water sub-phase at room temperature. All complexes showed near identical surface-pressure vs. area isotherms in which an exponential increase in surface pressure was observed upon decrease of the trough area (Fig. 2). The films collapsed at $53-59 \mathrm{mN} \mathrm{m}^{-1}$ with molecular areas of $78-81 \AA^{2}$. The stability of the Langmuir films were also evaluated by keeping the monolayers at the liquid-condensed phase for prolonged periods of time (>60 min) while monitoring the surface pressure. All complexes displayed excellent stability profiles (Fig. 2), thus giving the ideal situation for film deposition.

Langmuir-Blodgett deposition was carried out on either a square quartz slide $(30 \mathrm{~mm} \times 30 \mathrm{~mm}, 1 \mathrm{~mm}$ thick) for photophysical or a circular $\mathrm{CaF}_{2}$ window $(\varnothing=20 \mathrm{~mm}, 1 \mathrm{~mm}$ thick) for FT-IR studies. Monolayer deposition was observed on emersion (up-stroke) of the slides from the water sub-phase with transfer ratios $(\operatorname{tr})$ of $c a$. 1 indicating near complete coverage of the slides (Fig. S45 and S46 and Table S1, in the ESI $\dagger$ ). Successful transfer of the molecular units was confirmed by UV/vis-absorption and FT-IR (see below). UV/vis-absorption of the monolayer films retained the same spectral features as observed in solution

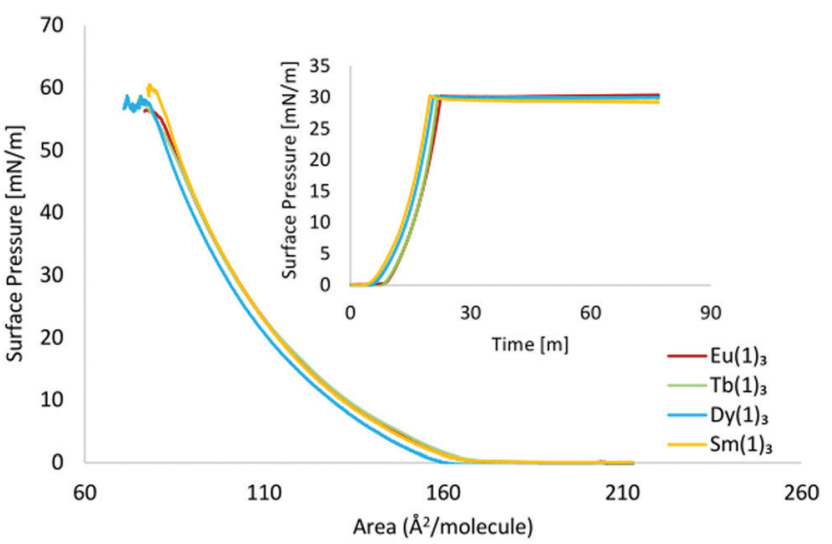

Fig. 2 - Surface pressure vs. area isotherms, of $\operatorname{Ln}(\mathbf{1})_{3}$ complexes (where $\mathrm{Ln}=\mathrm{Eu}^{3+}, \mathrm{Tb}^{3+}, \mathrm{Dy}^{3+}$ and $\mathrm{Sm}^{3+}$ ). Insert: Stability measurement of complexes - held at $30 \mathrm{mN} \mathrm{m}^{-1}$ for $>60 \mathrm{~min}$.

(i.e. absorption at $220 \mathrm{~nm}$ and broad absorption between 260 $290 \mathrm{~nm}$ ). Importantly, on transfer to the surface, the complexes retained their excellent emissive properties (Fig. 4). Photophysical properties (emission and excitation) remained unchanged on deposition when compared to the solution-based measurements (Fig. S58-S66, in the ESI†). The monolayer films remained highly emissive over extended periods of time with films still emissive after 6 months post deposition (Fig. S47, in the ESI $\dagger$ ). The $\operatorname{Dy}(\mathbf{1})_{3}$ monolayer film also retains its close to white single-component emission, with CIE coordinates of $x=$ 0.3416 and $\mathrm{y}=0.3876$ (Fig. 3). Multi-layering LB deposition studies were next carried out to both gain insight into the nature of the deposition process and to increase emission intensity. All complexes showed film deposition on emersion and partial deposition on immersion of the substrate which is indicative of a Y-type multi-layered film. ${ }^{38}$ Emission intensity for the $\mathrm{Eu}(\mathbf{1})_{3}$ complex was observed to increase as 3,5 , and 7 successive layers were deposited (Fig. S83 - see ESI $\uparrow$ for details). FT-IR spectra of an 8 layered $\mathrm{Eu}(\mathbf{1})_{3}$ film on a $\mathrm{CaF}_{2}$ slide showed distinct bands associated with the $\mathrm{C}=\mathrm{O}$ stretch at $1638 \mathrm{~cm}^{-1}$, notably in the region associated with the complex and not the base ligand, further indicating that the complex remains intact on deposition (Fig. S57 and Table S3, ESI $\dagger$ ).

With the near identical Langmuir film properties (i.e. isotherm and stability profiles) of these complexes, attempts to sequentially layer different $\mathrm{Ln}^{3+}$ complexes on each other were carried out. By multi-layering different lanthanide complexes, specifically $\operatorname{Eu}(\mathbf{1})_{3}$ with a second layer of $\operatorname{Tb}(\mathbf{1})_{3}$, we were able to 


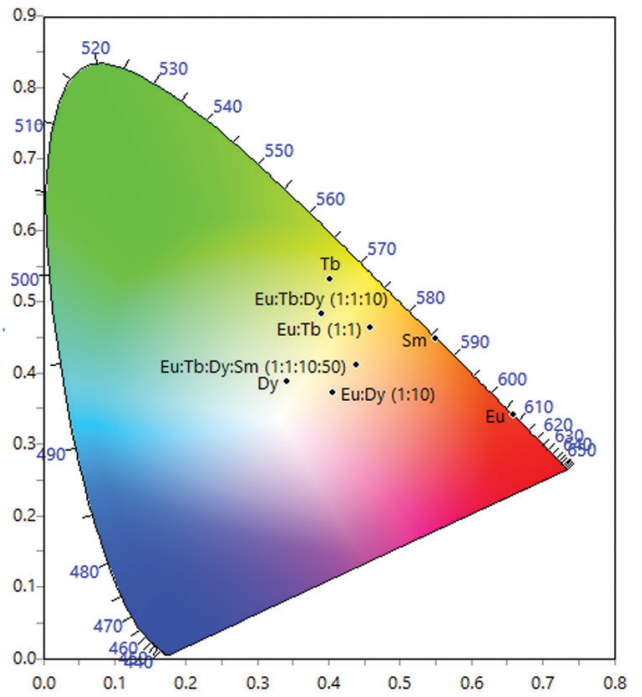

Fig. 3 - (a) $1931 \mathrm{CIE}$ chromaticity diagram with calculated CIE coordinated of monolayer LB films of $\mathrm{Eu}(\mathbf{1})_{3}, \mathrm{~Tb}(\mathbf{1})_{3}, \operatorname{Sm}(\mathbf{1})_{3} \operatorname{Dy}(\mathbf{1})_{3}, \mathrm{Eu}(\mathbf{1})_{3}: \mathrm{Tb}(\mathbf{1})_{3}(1: 1)$, $\mathrm{Eu}(\mathbf{1})_{3}: \operatorname{Dy}(\mathbf{1})_{3} \quad(1: 10), \operatorname{Eu}(\mathbf{1})_{3}: \operatorname{Tb}(\mathbf{1})_{3}: \operatorname{Dy}(\mathbf{1})_{3} \quad(1: 1: 10)$ and $\operatorname{Eu}(\mathbf{1})_{3}: \operatorname{Tb}(\mathbf{1})_{3}:$ $\operatorname{Dy}(\mathbf{1})_{3}: \operatorname{Sm}(\mathbf{1})_{3}(1: 1: 10: 50)$ see $\mathrm{ESI} \dagger$ for coordinates.

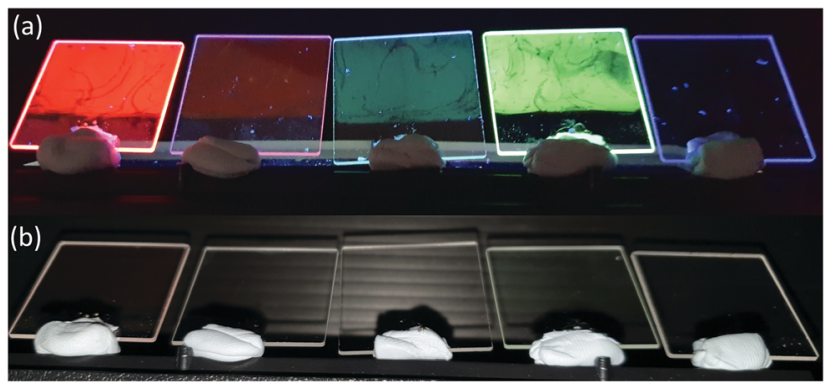

Fig. 4 - (a) Monolayer LB of $\mathrm{Eu}(\mathbf{1})_{3}, \operatorname{Sm}(\mathbf{1})_{3}, \mathrm{Dy}(\mathbf{1})_{3}, \mathrm{~Tb}(\mathbf{1})_{3}$ and blank slide under shortwave UV irradiation, and (b) without shortwave UV irradiation.

generate a dual emissive surface (which gave an overall yellow/ orange emission). Whilst multi-layering was found to increase overall emission intensity and give multiple emission bands, unfortunately the films were routinely non-uniform, as seen with the green, red and orange emissions observed (Fig. 5). In order to circumvent the issues observed when using a multilayered approach, we moved to a mixed amphiphile approach. We believed that with the different complexes having near identical Langmuir film isotherms, by mixing different amphiphiles together in solution, deposition should allow multi-emissive monolayers to be achieved.

Chloroform solutions for LB deposition were prepared containing different ratios of the emissive complexes. This approach allowed us to achieve relatively similar intensities from each lanthanide ion $\left(\mathrm{Ln}^{3+}\right)$ and tune the emission profile in solution before deposition. Initially we employed a dual emissive system consisting of a $1: 1$ ratio of $\mathrm{Eu}(\mathbf{1})_{3}$ and $\operatorname{Tb}(\mathbf{1})_{3}$ - the solution state emission profile showed both $\mathrm{Tb}^{3+}$ and $\mathrm{Eu}^{3+}$ emission and gave a yellow/ orange emission with CIE coordinates of $x=0.4530$ and $y=0.4828$ (Fig. S78 in the ESI†). The properties (isotherm and stability) of the

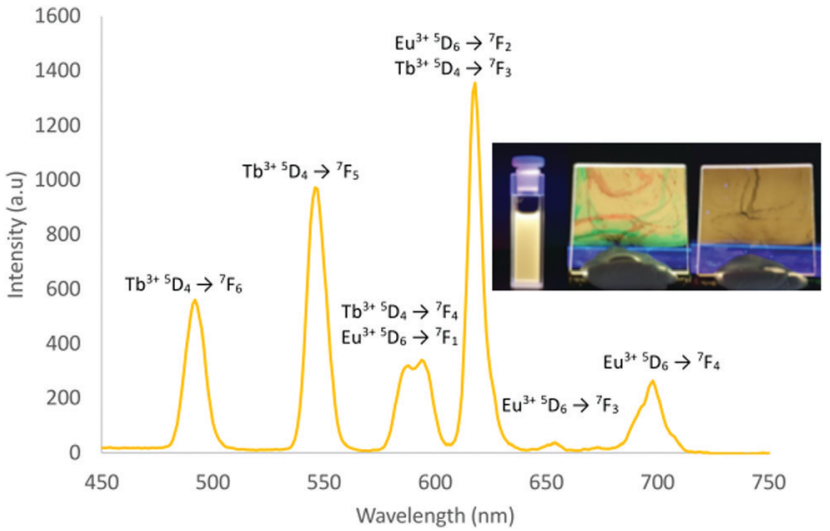

Fig. 5 - Steady-state emission from monolayered mixed $\mathrm{Eu}(1)_{3}: \mathrm{Tb}(1)_{3}$ $(1: 1)$ film. Images are of (left) $\mathrm{Eu}(1)_{3}: \mathrm{Tb}(1)_{3}(1: 1)$ in solution (middle) multilayered mixed film and (right) monolayer mixed amphiphile film under shortwave UV irradiation.

Langmuir film formed from this mixed amphiphile system were, as expected, near identical to the films of the mono-component systems (Fig. S68 and S69, in the ESI $\dagger$ ). Upon deposition of the mixed $\mathrm{Tb}^{3+} / \mathrm{Eu}^{3+}$ film onto a quartz slide, yellow/orange emission, similar to that seen in solution, was observed (Fig. 5). This mixed amphiphile approach appeared to achieve the same emission tuning as the multi-layered $\mathrm{Tb}^{3+} / \mathrm{Eu}^{3+}$ film, however the film has superior emission uniformity across the slide (Fig. 5, inset). For this reason, further deposition studies were carried out using the mixed amphiphile approach.

A dual emissive monolayer was also observed via mixed solutions of $\operatorname{Eu}(\mathbf{1})_{3}$ and $\operatorname{Dy}(\mathbf{1})_{3}$. At a 1:1 ratio the emission from $\mathrm{Dy}^{3+}$ is significantly weaker than the $\mathrm{Eu}^{3+}$ emission and is barely observable, however by increasing the ratio to $1: 10$ (Eu: Dy) we were able to achieve similar emission intensity for steady-state emission (Fig. S70, ESI $\dagger$ ). Attempts at colour tuning different combinations of $\operatorname{Dy}(\mathbf{1})_{3}: \operatorname{Eu}(\mathbf{1})_{3}$ and $\operatorname{Dy}(\mathbf{1})_{3}: \operatorname{Sm}(\mathbf{1})_{3}$ were carried out in solution in an attempt to improve overall white emission but were found ineffective (see ESI $\dagger$ for details).

With successful dual emissive films readily prepared, we next investigated the possibility of developing triply emissive, mixed amphiphile films by incorporating three emissive complexes. Indeed, a solution of $\operatorname{Eu}(\mathbf{1})_{3}, \operatorname{Tb}(\mathbf{1})_{3}$ and $\operatorname{Dy}(\mathbf{1})_{3}$ in a $1: 1: 10(\mathrm{Eu}: \mathrm{Tb}: \mathrm{Dy})$ ratio gave a triply emissive film where distinct emission from all three $\mathrm{Ln}^{3+}$ ions was obtained (Fig. S72, ESI $\dagger$ ). The final aspect of our study was to incorporate four visibly emitting lanthanide complexes into a quadruply emitting film. We extended the technique used to make dual and triply emissive films by incorporating $\mathrm{Sm}^{3+}$ as the fourth emitting complex with the optimum ratio of $1: 1: 10: 50\left[\operatorname{Eu}(\mathbf{1})_{3}: \operatorname{Tb}(\mathbf{1})_{3}: \operatorname{Dy}(\mathbf{1})_{3}: \operatorname{Sm}(\mathbf{1})_{3}\right]$ giving near equal emission intensities for each $\mathrm{Ln}^{3+}$ (Fig. 6).

X-ray photoelectron spectroscopy (XPS) was performed on films to confirm the atomic composition. XPS revealed the presence of $\mathrm{O}, \mathrm{N}$, and $\mathrm{C}$ on all films indicating the presence of $\mathbf{1}$ on the surface. Importantly, for all non-mixed monolayers, the distinct peaks associated with the $3 \mathrm{~d}_{3 / 2}$ and $3 \mathrm{~d}_{5 / 2}$ binding energy bands for lanthanide ions (see Fig S99-S102, ESI $\dagger$ ) were seen. In the case of $\operatorname{Eu}(\mathbf{1})_{3}, \operatorname{Tb}(\mathbf{1})_{3}$ and $\operatorname{Sm}(\mathbf{1})_{3}$ monolayer 


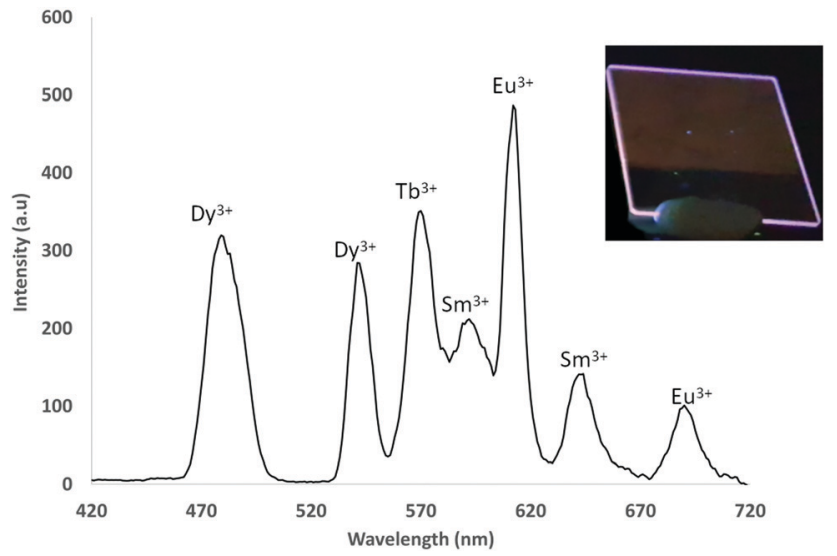

Fig. 6 - Quadruple steady-state emission from mixed monolayer LB film of $\mathrm{Eu}(\mathbf{1})_{3}: \mathrm{Tb}(\mathbf{1})_{3}: \operatorname{Dy}(\mathbf{1})_{3}: \operatorname{Sm}(\mathbf{1})(1: 1: 10: 50)$. Insert: Mixed multi-layered film under shortwave UV irradiation.

films, by comparing the relative signal area of the $3 \mathrm{~d}_{5 / 2}$ peak to the nitrogen 1s peak (and accounting for differences in photoelectron escape depths), a ratio of approx. 1:15 $\left(\mathrm{Ln}^{3+}: \mathrm{N}\right)$ was obtained, indicating the presence of the $(1: 3) \mathrm{M}: \mathrm{L}$ species on the surface (Fig. S107-S109, ESI $\dagger$ ). XPS was also carried out on the dual $(1: 1)$ and quadruple $(1: 1: 1: 1)$ mixed films. Results confirmed the presence of multiple $\mathrm{Ln}^{3+}$ ions (Fig. S103-S106, ESI $\dagger$ ).

To conclude, we have shown that using the amphiphilic ligand 1 , we are able to generate bright, visibly emissive $\operatorname{Ln}^{3+}$ complexes that are suitable for LB film deposition, thus generating surface immobilised luminescent materials. Furthermore, the near identical nature of the films has allowed us to generate rare examples of multi-emissive ultra-thin-films by taking a mixed amphiphile approach to LB film formation. In doing so we have observed monolayers with emission from two, three and four lanthanide ions. To the best of our knowledge this study presents the first examples of triple and quadruple emission from LB monolayers. Such mixed amphiphile, multi-emissive, monolayers have potential to generate new materials with a host of advanced properties. For example, by incorporating different analyte specific receptors on different amphiphilic complexes, systems capable of detecting four distinct analytes are possible. This study represents rare examples of multi-emissive surfaces, an area we are actively developing to generate more advanced surface immobilised supramolecular materials.

\section{Conflicts of interest}

There are no conflicts to declare.

\section{Notes and references}

1 D. B. Amabilino, D. K. Smith and J. W. Steed, Chem. Soc. Rev., 2017, 46, 2404-2420.
2 J. A. Kitchen, Coord. Chem. Rev., 2017, 340, 232-246.

3 S. V. Eliseeva and J.-C. G. Bünzli, Chem. Soc. Rev., 2010, 39, 189-227.

4 J.-C. G. Bünzli, Eur. J. Inorg. Chem., 2017, 5058-5063.

5 M. Hasegawa and A. Ishii, Coord. Chem. Rev., 2020, 421, 213458.

6 J.-C. G. Bünzli, Coord. Chem. Rev., 2015, 293-294, 19-47.

7 A. J. Amoroso and S. J. A. Pope, Chem. Soc. Rev., 2015, 44, 4723-4742.

8 J.-C. G. Bünzli, Trends Chem., 2019, 1, 751-762.

9 J.-C. G. Bünzli, Chem. Rev., 2010, 110, 2729-2755.

10 Z. Zhang, Y. Chen, H. Chang, Y. Wang, X. Li and X. Zhu, J. Mater. Chem. C, 2020, 8, 2205-2210.

11 O. Kotova, S. J. Bradberry, A. J. Savyasachi and T. Gunnlaugsson, Dalton Trans., 2018, 47, 16377-16387.

12 J. Wang, Y. Suffren, C. Daiguebonne, S. Freslon, K. Bernot, G. Calvez, L. Le Pollès, C. Roiland and O. Guillou, Inorg. Chem., 2019, 58, 2659-2668.

13 T. Sun, Y. Gao, Y. Du, L. Zhou and X. Chen, Front. Chem., 2021, 8.

14 S. SeethaLekshmi, A. R. Ramya, M. L. P. Reddy and S. Varughese, J. Photochem. Photobiol., C, 2017, 33, 109-131.

15 H. Brunckova, E. Mudra, L. Rocha, E. Nassar, W. Nascimento, H. Kolev, A. Kovalcikova, Z. Molcanova, M. Podobova and L. Medvecky, Appl. Surf. Sci., 2021, 542, 148731.

16 T. Wang, P. Li and H. Li, ACS Appl. Mater. Interfaces, 2014, 6, 12915-12921.

17 M. Martínez-Calvo, O. Kotova, M. E. Möbius, A. P. Bell, T. McCabe, J. J. Boland and T. Gunnlaugsson, J. Am. Chem. Soc., 2015, 137, 1983-1992.

18 M. A. Hernández-Rodríguez, C. D. S. Brites, G. Antorrena, R. Piñol, R. Cases, L. Pérez-García, M. Rodrigues, J. A. Plaza, N. Torras, I. Díez, A. Millán and L. D. Carlos, Adv. Opt. Mater., 2020, 8, 2000312.

19 H. Liu, T. Chu, Z. Rao, S. Wang, Y. Yang and W.-T. Wong, Adv. Opt. Mater., 2015, 3, 1545-1550.

20 N. Marets, S. Kanno, S. Ogata, A. Ishii, S. Kawaguchi and M. Hasegawa, ACS Omega, 2019, 4, 15512-15520.

21 J. Ma and B. Yan, Dyes Pigm., 2018, 153, 266-274.

22 M. Clemente-León, E. Coronado, Á. López-Muñoz, D. Repetto, T. Ito, T. Konya, T. Yamase, E. C. Constable, C. E. Housecroft, K. Doyle and S. Graber, Langmuir, 2010, 26, 1316-1324.

23 Q.-M. Fu, H. Fu, L. Hu, L. Liu, S.-Z. Liu, Z.-L. Du and W.-Y. Wong, J. Inorg. Organomet. Polym. Mater., 2012, 22, 97-104.

24 J. Ni, Q.-M. Fu, L. Liu, Z.-R. Gu, Z. Zhou, F.-B. Li, S.-X. Zhang, S.Z. Liu and Z.-L. Du, Thin Solid Films, 2013, 537, 247-251.

25 L. Liu, M. Chen, J. Yang, S.-Z. Liu, Z.-L. Du and W.-Y. Wong, J. Polym. Sci., Part A: Polym. Chem., 2010, 48, 879-888.

26 D. E. Barry, J. A. Kitchen, L. Mercs, R. D. Peacock, M. Albrecht and T. Gunnlaugsson, Dalton Trans., 2019, 48, 11317-11325.

27 D. E. Barry, J. A. Kitchen, M. Albrecht, S. Faulkner and T. Gunnlaugsson, Langmuir, 2013, 29, 11506-11515.

28 S. Sundaresan, J. A. Kitchen and S. Brooker, Inorg. Chem. Front., 2020, 7, 2050-2059.

29 D. J. Wales and J. A. Kitchen, Chem. Cent. J., 2016, 10, 72.

30 A. Galanti, O. Kotova, S. Blasco, C. J. Johnson, R. D. Peacock, S. Mills, J. J. Boland, M. Albrecht and T. Gunnlaugsson, Chem. Eur. J., 2016, 22, 9709-9723.

31 A. T. O'Neil, N. Zhang, J. A. Harrison, S. M. Goldup and J. A. Kitchen, Supramol. Chem., 2021, DOI: 10.1080/10610278.2021.1955120.

32 R. Jagannathan and S. Soundararajan, J. Coord. Chem., 1979, 9, 31-35.

33 T. Le Borgne, J.-M. Bénech, S. Floquet, G. Bernardinelli, C. Aliprandini, P. Bettens and C. Piguet, Dalton Trans., 2003, 3856-3868.

34 F. Renaud, C. Piguet, G. Bernardinelli, J.-C. G. Bünzli and G. Hopfgartner, Chem. - Eur. J., 1997, 3, 1646-1659.

35 M. Vijayakumar, K. Mahesvaran, D. K. Patel, S. Arunkumar and K. Marimuthu, Opt. Mater., 2014, 37, 695-705.

36 G. A. Crosby and J. N. Demas, J. Phys. Chem. A, 1971, 75, 991-1024.

37 A. S. Chauvin, F. Gumy, D. Imbert and J. C. G. Bünzli, Spectrosc. Lett., 2004, 37, 517-532.

38 M. C. Petty, In Langmuir-Blodgett Films: An Introduction, Cambridge University Press: Cambridge, 1996, pp. 39-64. 